\title{
RELAÇÃO DO TRIPÉ MACROECONÔMICO E A NOVA MATRIZ SOBRE A FORMAÇÃO BRUTA DE CAPITAL FIXO NO PERÍODO DE 1999 A 2014.
}

\author{
RELATION OF THE MACROECONOMIC TRIPOD AND THE NEW MATRIX ON THE \\ FORMATION OF FIXED CAPITAL FROM 1999 TO 2014.
}

\author{
Luis Miguel dos Santos Cerukovic - miguelcerukovic@gmail.com \\ Bacharel em Ciências Econômicas \\ Centro Universitário Moura Lacerda(CUML) -Ribeirão Preto - São Paulo - Brasil \\ Professor Me. Cláudio Pereira Bidurin \\ Centro Universitário Moura Lacerda(CUML) - Ribeirão Preto - São Paulo - Brasil
}

\begin{abstract}
RESUMO
O investimento tem função primordial no crescimento econômico sustentável de uma nação, de modo a incentivá-lo o governo realiza uma série de políticas econômicas. O objetivo deste artigo é analisar as variáveis relacionadas às políticas econômicas de dois recentes e distintos períodos da economia brasileira, o tripé macroeconômico e a nova matriz econômica, fornecendo às bases teóricas que compõe as atuais políticas econômicas de fomento e amparo às unidades privadas, relevantes a economia em desenvolvimento brasileira. Este estudo tem como base a Teoria Geral de Keynes e o pressuposto de que o Estado é o ente econômico que pode fomentar a economia, em momentos de crise, de forma a estimular o pleno emprego e realizar a manutenção do bem-estar no longo prazo, assim como definir taxas de juros que possibilitem a participação e o interesse dos empresários capitalistas de realizarem investimentos, que permitirão o crescimento econômico da nação. Contudo, o presente artigo chama atenção para o nível de intervenção na economia, precavendo sobre os possíveis ganhos e perdas causados pela intervenção do estado e neste trabalho são analisadas as políticas econômicas predominantes no período de 1999 a 2014.
\end{abstract}

Palavras-chave: Economia Brasileira. Tripé Macroeconômico. Nova Matriz Econômica. Investimento Econômico.

\begin{abstract}
Investment has a primordial role in the sustainable economic growth of a nation, so as to encourage it the government carries out a series of economic policies. The objective of this article is to analyze the variables related to the economic policies of two recent and distinct periods of the Brazilian economy, the macroeconomic tripod and the new economic matrix, providing the theoretical bases that compose the current economic policies of support and support to the relevant private units the Brazilian developing economy. This study is based on the General Theory of Keynes and the assumption that the State is the economic entity that can foster the economy in times of crisis in order to stimulate full employment and maintain longterm well-being, as well as to define interest rates that allow the participation and interest of capitalist entrepreneurs to make investments that will allow the economic growth of the nation. However, the present article draws attention to the level of intervention in the economy, taking
\end{abstract}




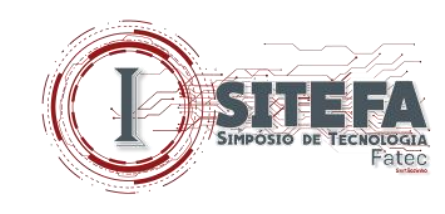

into account the possible gains and losses caused by state intervention, and in this work the predominant economic policies from 1999 to 2014 are analyzed.

Keywords: Brazilian economy. Macroeconomic tripod. New Economic Matrix. Economic Investment.

\section{DOI:}

\section{INTRODUÇÃO}

A escolha entre investir e poupar no presente impacta no futuro, haja vista Teoria Geral do emprego, do juro e da moeda, Keynes (1983) o equilíbrio macroeconômico é alcançado pela igualdade entre oferta agregada e demanda agregada e que, como é mostrado na figura abaixo, a demanda agregada é dependente da demanda por bens de consumo e por bens de capital, que por sua vez são dependentes do nível de renda e investimento, logo como exposto por Keynes, entender as flutuações de renda e investimento possibilitam entender os movimentos da economia.

A decisão por investir ou poupar ainda abarca o cenário ao qual o capital está exposto, com explicado por Casagrande (1996), dessa forma quanto maior for o nível de incerteza probabilística menor será a propensão a investir, de modo a evitar o nível alto de poupança o aumento da taxa de juros se dá de forma compensatória. Quando se têm um país onde é muito arriscado investir, ou seja, que exista a possibilidade de não pagamento da dívida nacional (títulos) existirá uma taxa de juros maior em relação a outros países com menor grau de risco, a essa diferença se dá o nome de prêmio pelo risco.

Figura 1 - A demanda agregada segundo Keynes (1983)

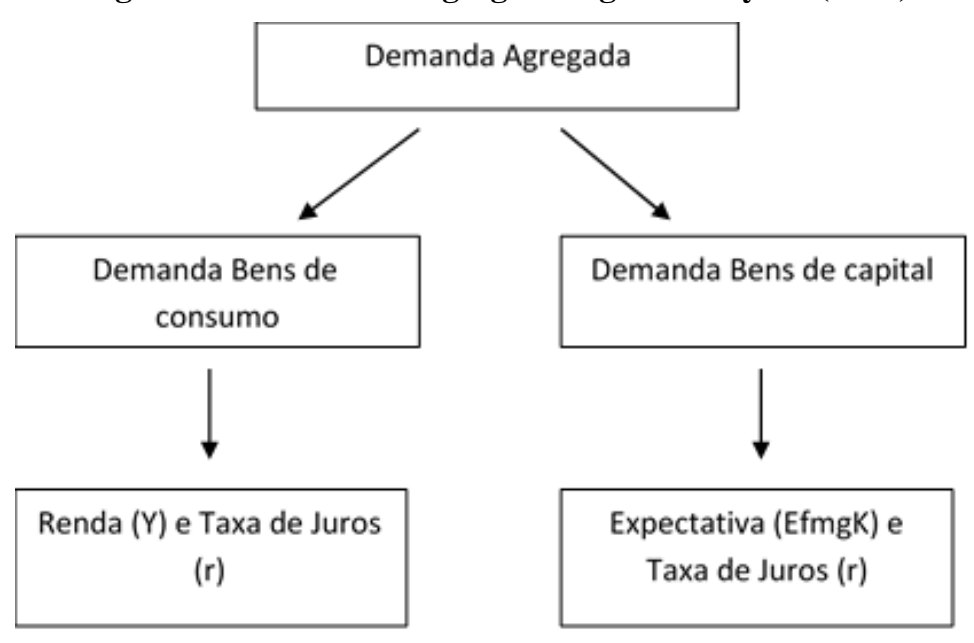

Fonte: adaptada pelo autor 


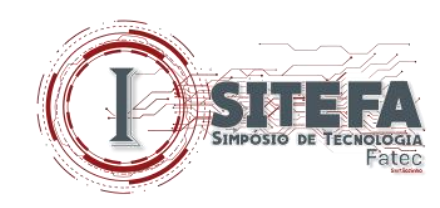

O ambiente econômico é tomado por incertezas, conquanto, os empresários têm que tomar decisões sobre a produção futura em um mesmo contexto, dessa forma aquele que obtiver maior vantagem irá conseguir destacar-se. Na teoria Schumpeteriana apresentada Schumpeter (1997) o empresário é retratado com suma importância e isso ocorre por conta da relação que o autor descreve entre as inovações e o crescimento da produção, de forma que as inovações e o crescimento da produção, de forma que as inovações possibilitam vantagens que por sua vez levam ao aumento da produção. Schumpeter (1997) chama atenção para o papel dos bancos na economia, que em sua teoria devem fornecer as bases de crédito aos empresários de forma que assegurem que suas inovações sejam produzidas, porém, as políticas de subsídio devem ser controladas de maneira a não desencadear uma crise nas contas nacionais.

\section{TRIPÉ MACROECONÔMICO}

Como apresentado no livro Economia Brasileira Contemporânea de Giambiagi (2011) em 1995 o México enfrentava uma grave crise a respeito de suas divisas, o que levou a equipe econômica brasileira questionar sobre os resultados de um regime rígido de câmbio. Em março do mesmo ano o governo optou por realizar uma desvalorização controlada e proceder com elevação da taxa de juros nominais, demonstrando aos investidores internacionais seu empenho em defesa da política cambial, esta postura atraiu capital estrangeiro. No entanto o endividamento externo, realizados para financiar o déficit em conta corrente, e os investimentos estrangeiros diretos que elevaram o pagamento de juros e lucros ainda foram agravados em 1998 com os efeitos da crise internacional.

Com a elevada dívida do país e a preocupação com uma possível desvalorização da moeda, o governo recorre ao FMI no final de 1998 que empresta ao país US\$ 41,5 bilhões sob a condição de realização de um ajuste fiscal, entretanto, o mercado não estava convencido sobre a capacidade do Brasil e não foi possível que o país contivesse a evasão de capital, o governo ainda tentou aumentando a taxa de juros, contudo, apenas piorou a situação gerando recessão econômica.

Desta forma a partir de janeiro de 1999 o país opta pelo regime de câmbio flutuante e o real desvaloriza $40 \%$ nos dois meses seguintes, no entanto dado o enfraquecido cenário interno 


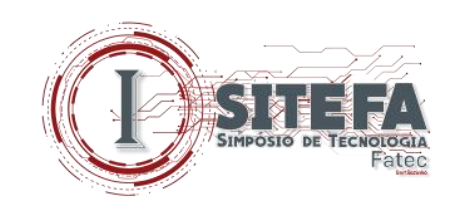

e a elevada taxa de juros a inflação manteve-se estável. Surge assim o primeiro item do que viria a ser chamado de tripé macroeconômico, o câmbio flutuante.

Para cumprir o acordo com o FMI o governo precisou reduzir os gastos e aumentar impostos, em busca de um superávit primário, assim em junho de 1999 como balizador da política monetária o governo passa a adotar o regime de metas de inflação, que consiste em estabelecer uma meta, a ser cumprida, para a variação do IPCA e em 2000 foi aprovada a Lei de Responsabilidade Fiscal que funciona como orientação as finanças públicas sobre teto de gastos com pessoas e limites de endividamento. Assim, são apresentados os últimos dois itens que compõe o tripé macroeconômico, metas fiscais e metas de inflação.

\subsection{Nova Matriz}

A partir de agosto de 2011, houve uma mudança nas políticas econômicas, começando pelo afrouxamento da política monetária, que com as sucessivas quedas da taxa básica de juros que passaram de 12,5\% em agosto de 2011 para 7,25\% em outubro do ano seguinte até abril de 2013, quando inicia-se outro período de elevação da taxa. O IPCA em 2012 acumulou alta de $5,84 \%$ no ano ficando longe do centro da meta de 4,5\% assim como nos outros anos a inflação não alcançou o centro da meta. O governo passou a intervir de maneira mais direta sobre o sistema de preços visando controle sobre a inflação, como o ajuste artificial dos preços administrados, entre outras que estimularam a demanda e colaborou para o descontrole sobre a inflação o que representou um rompimento com um dos itens do tripé regime de metas para a inflação.

Ainda sobre os gastos do governo que se elevaram sem a contrapartida de aumento nas receitas, somado a desaceleração do crescimento provocaram superávits primário menores chegando a um déficit de 0,63\% do PIB (Produto Interno Bruto) em 2014, onde se contrasta com a lei de responsabilidade fiscal, outro item pertencente ao tripé macroeconômico.

O regime de câmbio flutuante foi mantido, todavia, o Banco Central praticou um processo de hedge contínuo sobre o câmbio, intervindo diariamente, objetivando manter a desvalorização da moeda, rompendo com o item restante do tripé 


\section{(1)}

\section{PROCEDIMENTOS METODOLÓGICOS E DESCRIÇÃO DAS VARIÁVEIS}

O trabalho utiliza dados das contas nacionais trimestral divulgado pelo Instituto Brasileiro de Geografia e Estatística (IBGE), séries divulgadas pelo Banco Central e pesquisas Instituto de Pesquisa Econômica Aplicada (IPEA) e Fundação Getúlio Vargas (FGV). Com o objetivo de analisar o investimento, sob as condições de políticas econômicas adotadas pelo governo na vigência do tripé macroeconômico e da nova matriz macroeconômica, a metodologia aplicada foi influenciada pelos trabalhos de Melo e Rodrigues Júnior (1998) e Alves e Luporini (2008), inclusive as variáveis fixas do modelo tem como base as variáveis propostas no trabalho de Alves e Luporini (2008), com adequações.

A variável dependente do estudo é o investimento que no trabalho é representado pela Formação Bruta de Capital Fixo (FBCF), que conforme definição do IBGE registra a ampliação da capacidade produtiva futura de uma economia por meio de investimentos correntes em ativos fixos.

A equação tida como fixa é composta pelo PIB (Y) que é a soma de tudo que é produzido no país, o nível de utilização da capacidade instalada (UTCAP) mede o nível de atividade da indústria mostrando a porcentagem do parque industrial que está trabalhando e a taxa de juros real (R), que não segue a mesma metodologia adotada por Alves e Luponi ou Luporini (2010), que utilizou a série do CDB deflacionada pelo IGP-DI, neste trabalho a taxa de juros real é a TJLP utilizada para o cálculo dos financiamentos fornecidos pelo BNDES no período analisado deflacionada pelo IPCA que o governo reconhece como a inflação, ainda a taxa de juros real acrescenta ao modelo o custo de captação de capital.

As variáveis que são testadas individualmente no modelo são o emprego formal $(\mathrm{N})$, série divulgada mensalmente pelo MTE, para aplicação no modelo foi feita uma média trimestral, a utilização da série reside sob a oportunidade de testar um postulado keynesiano que o nível de emprego é dado pelo mercado por meio da demanda efetiva, que é composta por gastos com investimento e consumo. O desembolso do BNDES (DESEMB) é uma série com divulgação mensal e para o estudo é utilizado a média trimestral da mesma, sua inserção ao modelo reside em representar a teoria schumpeteriana que prioriza o empreendedor e por ser Schumpeter o idealizador do moderno banco de fomento a série tem por objetivo demonstrar os estímulos as empresas. A despesa do tesouro nacional (DESP.T) é publicada pela secretária 


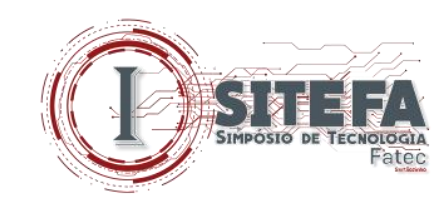

do tesouro nacional e é divulgada mensalmente, porém foi incorporada ao modelo sua média trimestral, sua participação no modelo visa fornecer bases para o entendimento da política fiscal no período estudado. A série que representa a poupança $(\mathrm{S})$ é o total aplicado em caderneta de poupança é divulgada pelo Banco Central, com intervalos mensais e para o modelo foi usada a média trimestral, estes dados estão presentes no modelo com o objetivo de avaliar a questão da escolha intertemporal proposta por Fisher, na qual a escolha de postergar o consumo levará a uma poupança futura e essa poupança no presente indicará a possibilidade de consumo futuro de bens de consumo e de capital. As reservas internacionais de liquidez total (RI) representam a última variável estudada no modelo, também são de divulgação mensal pelo Banco Central e foi utilizada a média trimestral na análise, sua presença deve-se ao entendimento da política cambial empregada no período.

Em suma as variáveis analisadas são:

- $\quad \mathrm{FBCF}=$ Formação Bruta de Capital Fixo, valores correntes em milhões de Reais, série Contas Nacionais Trimestrais, fonte IBGE.

- $\quad$ PIB $=$ Produto Interno Bruto, valores correntes em milhões de Reais, série Contas Nacionais Trimestrais, fonte IBGE.

- $\quad$ UTCAP = Sondagem Industrial - Nível de Utilização da Capacidade, fonte FGV - Sondagem, código 1005040.

- $\quad \mathrm{R}=$ Taxa de Juros Reais: TJLP (Taxa de juros de longo prazo), fonte IBGE, deflacionada pelo IPCA, fonte IBGE.

- $\quad \mathrm{N}=$ Emprego Formal, fonte MTE (Ministério do trabalho e emprego), código 25239.

- $\quad$ DESEMB = Desembolso do sistema BNDES, em milhões, código 7415.

- $\quad$ DESP.T = Despesa do tesouro nacional, operações de crédito em milhões, código 2273.

- $\quad \mathrm{S}=$ Caderneta de poupança, saldo em milhões, fonte Banco Central, código 7836.

- $\quad \mathrm{RI}=$ Reservas Internacionais - Conceito liquidez total, em milhões, fonte Banco Central, código 3546. 


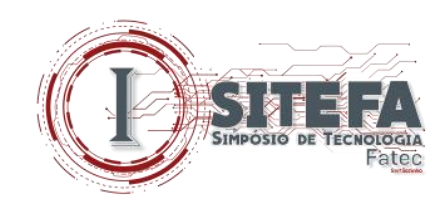

\section{RESULTADOS E DISCUSSÃO}

Os resultados e as discussões são apresentadas nas subseções a seguir.

\subsection{Tripé Macroeconômico}

As equações de investimento foram estimadas pelo método de Mínimos Quadrados Ordinários, utilizando dados trimestrais para o período do primeiro trimestre de 1999 ao quarto trimestre de 2014 e para a estimação as séries foram divididas em dois períodos, o primeiro período trata sobre o tripé macroeconômico (tabela 1) e o período correspondente é do primeiro trimestre de 1999 ao segundo trimestre de 2011, enquanto que o segundo período é iniciado no terceiro trimestre de 2011 e, a título de análise, encerrado no quarto trimestre de 2014 o qual representa a nova matriz econômica (tabela 2).

A primeira (EQ1), segunda (EQ2) e terceira (EQ3) equações da tabela 1 apresentaram capacidade explicativa, entretanto, torna-se inviável analisar as mesmas, pois, apenas a variável (Y) apresenta-se significativa.

A quarta equação (EQ4) busca representar, por meio da inclusão da variável de despesa do tesouro nacional (DESP.T), a responsabilidade fiscal do governo um item do tripé macroeconômico e essa variável demonstrou, ao lado de $\mathrm{Y}$, capacidade explicativa e significância. Desta forma e dado a relação inversamente proporcional a FBCF, é possível afirmar que no período um aumento de gastos do governo iria impactar negativamente a FBCF enquanto que uma redução provocaria um efeito positivo sobre FBCF.

Todas as variáveis da quinta equação (EQ5), que buscou demonstrar a relação direta da poupança com o investimento, como proposta por Fisher, apresentaram ser significativas a 1\%, exceto a taxa de juros, e capacidade explicativa ( $\mathrm{R}^{2}$ ajustado) de 0,99 . Constatando que quando há participação da poupança a variável UTCAP apresenta-se significativa e diretamente proporcional a FBCF o que confirma o pressuposto econômico que a escolha de poupar impacta diretamente o investimento.

A sexta equação (EQ6) apresenta a política cambial por meio das reservas internacionais de liquidez total. A relação de RI com FBCF é significativa e diretamente proporcional, o que traduz que a relação de um câmbio flutuante estimula a formação de FBCF. 


\section{(1) SIIEFE}

Como nos trabalhos de Reis et al (1999) e Alves e Luporini (2008) a taxa de juros não é significativa para a determinação da equação, a taxa de custo do capital é reconhecidamente importante na determinação do investimento, porém, existe dificuldade de obter coeficiente significativos para sua representação empírica.

Tabela 1 - Resultados do modelo obtidos a partir do GRETL

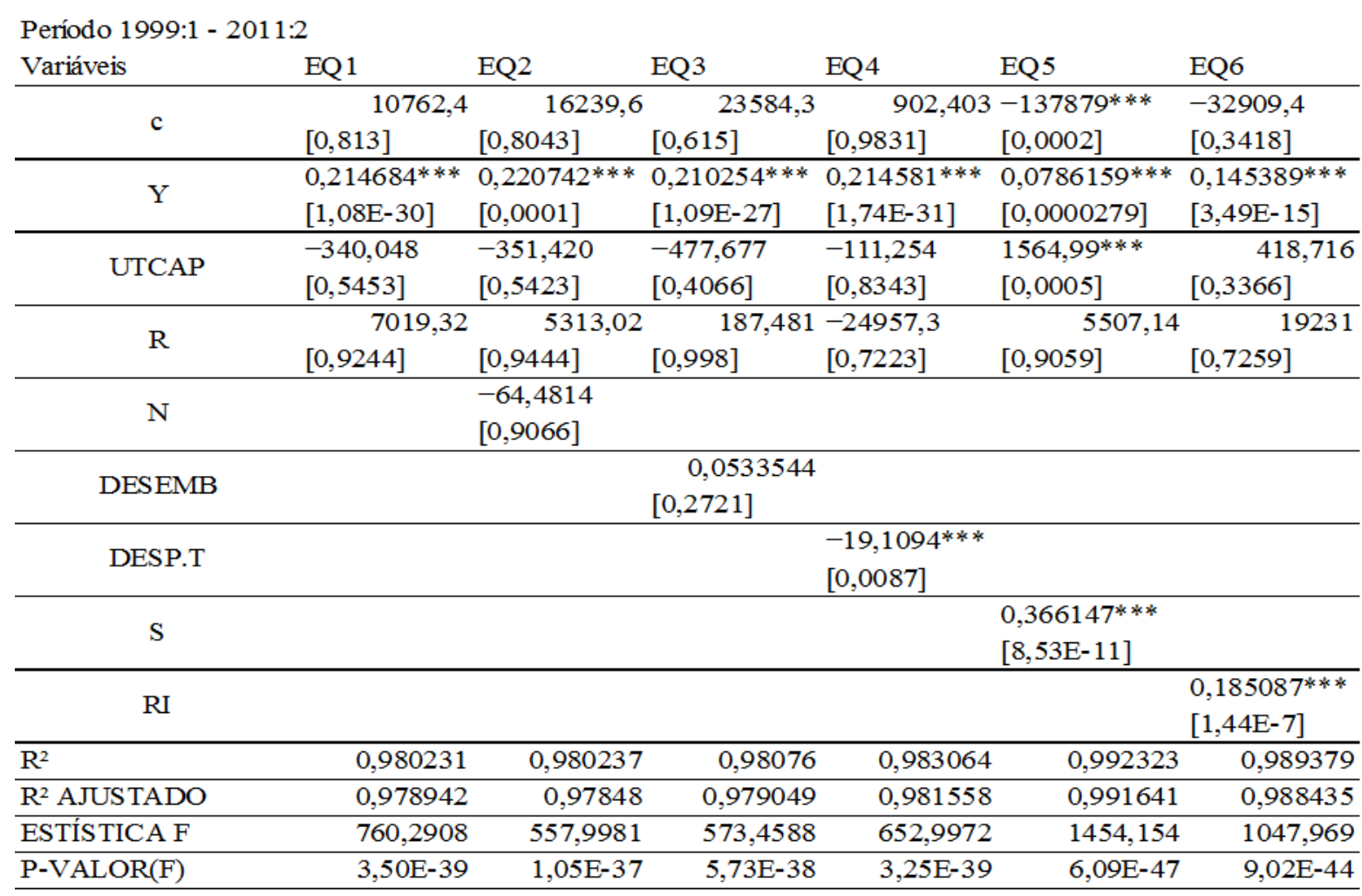

Fonte: o autor

(Os valores em colchetes indicam o p-valor das variáveis e $(* * *),(* *)$ e $(*)$ indicam o nível de significância a $1 \%, 5 \%$ e $10 \%$, respectivamente).

\subsection{Nova Matriz}

O período utilizado para a análise da nova matriz inicia-se no terceiro trimestre de 2011 e tem fim no quarto trimestre de 2014.

A primeira (EQ1), quarta (EQ4) e sexta (EQ6) equações apresentam significância apenas na variável Y, desta forma, somente é possível afirmar a relação diretamente proporcional do PIB com a FBCF. 


\section{(1) 1 ane}

Na segunda equação (EQ2) a variável Y não possui significância, contudo, a variável do emprego $(\mathrm{N})$ apresenta-se significativa e diretamente proporcional a FBCF, demonstrando que no período da nova matriz a FBCF reagiu diretamente à expansão do emprego.

A terceira equação (EQ3) conta com a variável DESEMB, que foi inserida ao modelo para demonstrar um marco da nova matriz que foi a expansão do gasto do governo por meio do BNDES, não obstante o comportamento desta variável foi inversamente proporcional a FBCF no período, sendo assim, pode ser entendido que houve ineficiência na destinação destes recursos. Ainda quando adicionada DESEMB a equação, UTCAP ganha significância e mostrase diretamente proporcional a FBCF, assim como o PIB.

A quinta equação (EQ5) demonstra Y com relação inversa a FBCF e quando essa relação é dada a variável, em todas as equações estudadas, não foi significante. E UTCAP apesar de possuir significância a $10 \%$, não será considerada neste trabalho, pois a metodologia adotada estabelece um nível de mínimo $5 \%$.

Tabela 2 - Resultados do modelo obtidos a partir do GRETL

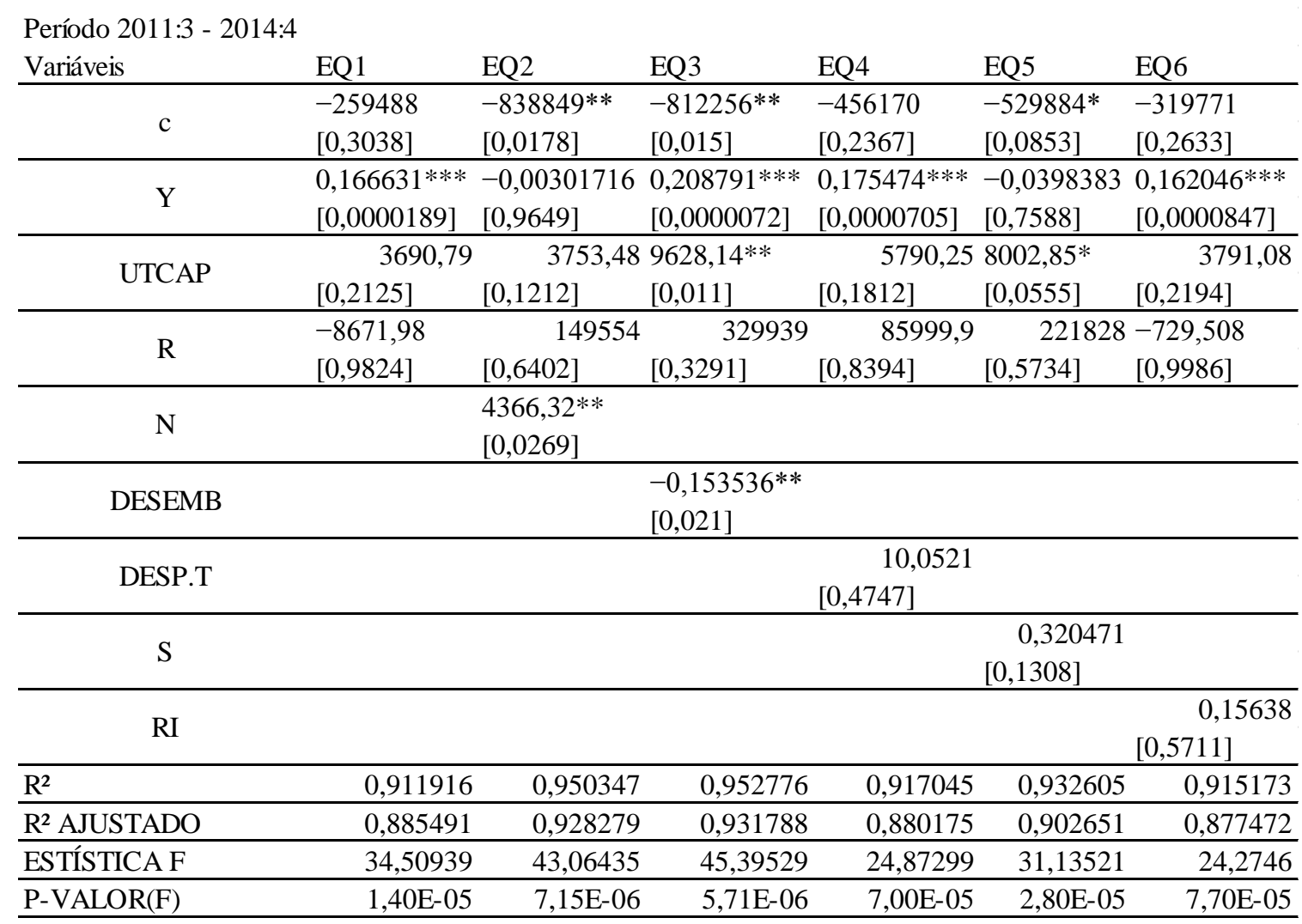

\section{Fonte: o autor}

(Os valores em colchetes indicam o p-valor das variáveis e $(* * *),(* *)$ e (*) indicam o nível de significância a $1 \%, 5 \%$ e $10 \%$, respectivamente) 


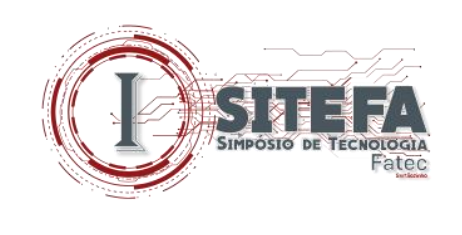

\section{CONSIDERAÇÕES FINAIS}

Por investimento privado entendem-se aplicações financeiras de caráter permanente, com o objetivo de gerar rendimentos futuros, de modo que para uma empresa realizar investimentos deve haver estabilidade econômica ou perspectivas de um futuro estável. As mutabilidades das decisões sobre investimento são responsáveis pelas oscilações econômicas enquanto que a insuficiência de investimento causa baixas taxas de crescimento da economia.

Tendo como ponto de partida a Teoria Geral de Keynes, utilizando-se da teoria Schumpeteriana para declarar a participação do empresário, este artigo buscou elucidar a importância do nível de investimento em uma economia, porque como é demonstrada pelos autores aqui apresentados é a chave para entender os movimentos econômicos.

As teorias apresentadas possuem grande relevância no cenário macroeconômico recente brasileiro, sendo assim, espera-se que este artigo possa contribuir em pesquisas futuras.

Para o período do tripé macroeconômico o emprego formal e os desembolsos do BNDES não são significativos, enquanto que as variáveis não significativas para a política da nova matriz foram as despesas do tesouro, poupança e reservas internacionais.

É possível afirmar, empiricamente, que quando adotado o tripé macroeconômico a formação bruta de capital fixo foi afetada pelo controle orçamentário do governo, influenciada pelo acúmulo de poupança e também pela situação das reservas internacionais.

Em relação à nova matriz econômica é possível afirmar, empiricamente, que os desembolsos do BNDES, afetaram negativamente a formação bruta de capital fixo.

\section{REFERÊNCIAS}

ALVES, Joana Duarte Ouro; LUPORINI, Viviane. Evolução da Teoria do Investimento e Análise Empírica para o Brasil. 2008. 19 p. Dissertação de Mestrado (Mestrado em economia)- UFF, Rio de Janeiro, 2008.

CASAGRANDE, Elton Estaqui. Os fundamentos keynesianos da decisão de investir.Perspectivas, São Paulo, p. 33-47,1996.

GIAMBIAGI, Fábio et al. Economia Brasileira Contemporânea. 2. ed. Rio de Janeiro:Elsevier, 2011. 290 p. 
KEYNES, J. M. A Teoria Geral do Emprego, do Juro e da Moeda. São Paulo: Abril Cultural, 1983.

SCHUMPETER, Joseph Alois . Teoria do desenvolvimento econômico: uma investigação sobre lucros, capital, crédito, juro e o ciclo econômico. São Paulo: Nova Cultural, 1997. 